\title{
Determination of Mesothelin Levels in Pleural Effusion Does Not Help Predict Survival of Patients With Malignant Pleural Mesothelioma
}

\author{
VINCENZO FONTANA ${ }^{1}$, MARIA PIA PISTILLO ${ }^{2}$, ANTONELLA VIGANI $^{3}$, PIER ALDO CANESSA $^{4}$, \\ GIOVANNI BERISSO ${ }^{5}$, UGO GIANNONI ${ }^{6}$, PAOLA FERRO $^{7}$, MARIA CRISTIANA FRANCESCHINI $^{7}$, \\ ROBERTA CAROSIO ${ }^{2}$, MARIKA TONARELLI $^{7}$, CRISTIANA ROSSI $^{7}$, PAOLO DESSANTI $^{7}$ and SILVIO RONCELLA ${ }^{7}$ \\ ${ }^{I}$ Clinical Epidemiology Unit, IRCCS Ospedale Policlinico San Martino, Genoa, Italy; \\ ${ }^{2}$ Tumor Epigenetics Unit, IRCCS Ospedale Policlinico San Martino, Genoa, Italy; \\ ${ }^{3}$ Oncology Division, Azienda Sanitaria Locale n. 5 "Spezzino", La Spezia, Italy; \\ ${ }^{4}$ Pneumology Division, Azienda Sanitaria Locale n. 5 "Spezzino", La Spezia, Italy; \\ ${ }^{5}$ Medicine Division, Azienda Sanitaria Locale n. 5 "Spezzino", La Spezia, Italy; \\ ${ }^{6}$ Radiodiagnostic Division, Azienda Sanitaria Locale n. 5 "Spezzino", La Spezia, Italy; \\ ${ }^{7}$ Histopathology and Cytopathology Division, Azienda Sanitaria Locale n. 5 "Spezzino", La Spezia, Italy
}

\begin{abstract}
Aim: This study evaluated the prognostic value of soluble mesothelin-related protein (SMRP) levels in pleural effusions (PE) from patients with pleural mesothelioma (MPM). Patients and Methods: SMRP level in PE was tested using an enzyme-linked immunosorbent assay (ELISA) in 109 patients with MPM at diagnosis before any treatment. The Kaplan-Meier method and the Cox regression were applied to compare overall survival probabilities across tertile categories of SMRP level. Results: No significant differences in Kaplan-Meier overall survival probabilities among the SMRP categories were found. A statistically non-significant trend for increased death rate ratio $(R R)$ was computed $(p=0.327)$ when the higher ( $>46.5 \mathrm{nM}, R R=1.38$ ) and intermediate (8.5-46.5 $n M, R R=1.18) S M R P$ categories were compared to the lower category $(<8.5 n M, R R=1.00)$. Cox regression modelling including a restricted cubic spline showed a moderately rising non-linear trend in death rate. Conclusion: The SMRP level in PE does not appear to have prognostic significance and its detection is not recommended in routine clinical management of patients with MPM.
\end{abstract}

Correspondence to: Dr. Silvio Roncella, Ph.D., Servizio di Anatomia ed Istologia Patologica, Ospedale Sant'Andrea, Via Mario Asso n. 2, 19124 La Spezia, Italy. Tel: +39 0187604560, Fax: +390187604560, e-mail: silvio.roncella@gmail.com

Key Words: Mesothelioma, mesothelin, pleural effusion, prognosis.
Malignant pleural mesothelioma (MPM) is typically an asbestos-related tumor, arising from mesothelial cells of the pleura, with a worldwide incidence increasing over the past decade and a peak expected in 2020 (1). MPM is a highly aggressive tumor with a poor prognosis (median survival ranges from 8 to 14 months from diagnosis) and limited treatment options. Indeed, conventional chemotherapy, alone or in combination with surgery with/without radiotherapy, is often ineffective. New therapeutic strategies such as immunotherapies, targeted therapies or combinations of novel drugs are under investigation (2). Pleural effusion (PE) is the first clinical sign of MPM in about $70 \%$ of MPM cases at presentation. PE, routinely taken by thoracentesis, allows the pathologist to carry out cytological diagnosis and provides the opportunity to evaluate soluble biomarkers important for diagnosis, prognosis and prediction of therapy response (1).

Routine determination of prognostic markers in MPM at diagnosis is very important as it helps the clinician to identify those patients who need surgery or more aggressive therapies or more attention during follow-up $(3,4)$.

In recent years, some new molecules have been proposed for evaluating the prognosis of MPM. Even though they need confirmation by others, osteopontin, fibulin-3, high-mobility group box 1 and soluble mesothelin-related protein (SMRP) appear very interesting (5). In particular, the use of the level of SMRP has shown promising results and has been widely studied (6-8). SMRP originates from mesothelin, a 40-kDa cell-surface glycoprotein with putative functions in cell-tocell adhesion. It is expressed by normal mesothelial cells and overexpressed by various types of cancer, including MPM $(9,10)$. SMRP is directly produced by malignant cells and 
can be secreted in PE and blood $(11,12)$. The level of SMRP in PE and serum has been found to be significantly increased in patients with MPM and the US Food and Drug Administration has approved SMRP detection for the diagnosis and monitoring of MPM (13-16).

However, the prognostic role of SMRP in PE in patients with MPM is not yet well defined and requires further investigation. To the best of our knowledge, only two studies have investigated the prognostic value of SMRP in PE but their results were divergent and not conclusive (17-19).

The aim of the present study was to clarify the prognostic significance of PE SMRP level with regard to its routine clinical application. This study was carried out on Italian patients with MPM for whom data are not yet available in the literature.

\section{Patients and Methods}

Patients. This study included 109 patients with MPM who had developed PE at diagnosis. All PEs were collected by thoracentesis between March 2008 and July 2011 before any treatment at the Division of Pneumology (ASL5, La Spezia, Italy).

MPM diagnosis was made on the basis of clinical signs, imaging data, cytological examination of PE and, whenever possible, by thoracoscopic biopsy examination (hematoxylin-eosin staining combined with immunohistochemistry).

Retrospectively, data were collected on the characteristics of the patients including age, sex, histotype, smoking habit (current/former smokers $v s$. non-smokers), history of asbestos exposure, symptoms such as chest pain and dyspnea, Eastern Cooperative Oncology Group performance status (ECOG-PS), International Mesothelioma Interest Group stage, granulocyte/lymphocyte ratio, platelet count and therapy (Table I).

The study protocol was approved by the Liguria Region Ethics Committee (P.R. 207REG2014). All patients were enrolled in the study after written informed consent was given.

Patient treatment. Sixty-eight out of 109 patients with MPM $(62.4 \%)$ were treated with local standard care and received first-line therapy and $18(16.5 \%)$ supportive care only. Among treated patients, $60(88.2 \%)$ underwent pemetrexed plus cisplatin or carboplatin and eight (11.8\%) gemcitabine plus carboplatin or cisplatin. Twenty-four patients $(22.0 \%)$ also received second-line therapy (pemetrexed plus cisplatin). For 23 out of 109 patients $(21.1 \%)$, the therapeutic regimen was unknown since they moved to other hospitals (Table I).

Detection assay for soluble mesothelin-related peptides. Aliquots from $\mathrm{PE}$ were centrifuged $\left(1,500 \times g\right.$ for $10 \mathrm{~min}$ at $\left.4^{\circ} \mathrm{C}\right)$ and the supernatant was stored at $-20^{\circ} \mathrm{C}$ until the SMRP analysis was performed. SMRP levels were tested in duplicate using the MesoMark enzyme-linked immunosorbent assay kit (Fujirebio Diagnostic, Malvern, PA, USA) with a limit of detection for the assay of $0.3 \mathrm{nM}$ according to the manufacturer's instructions.

Statistical analyses. Descriptive statistics (means, percentiles and range) and analysis of contingency tables were used to explore baseline patient characteristics. In particular, granulocyte/ lymphocyte ratio, platelet count and SMRP level in PE were
Table I. Characteristics of patients with malignant pleural mesothelioma analyzed for soluble mesothelin-related protein $(S M R P)(N=109)$.

\begin{tabular}{|c|c|c|}
\hline Characteristic & & $\mathrm{N}(\%)$ \\
\hline Age at diagnosis, years & Median (range) & $74(45-98)$ \\
\hline \multirow[t]{2}{*}{ Gender, n (\%) } & Male & $93(85.3)$ \\
\hline & Female & $16(14.7)$ \\
\hline \multirow[t]{2}{*}{ Smoking habit, n (\%) } & Non-smoker & $47(43.1)$ \\
\hline & Current/former smoker & $62(56.9)$ \\
\hline \multirow[t]{2}{*}{ Asbestos exposure, $\mathrm{n}(\%)$} & Unexposed & $43(39.5)$ \\
\hline & Exposed & $66(60.5)$ \\
\hline \multirow[t]{2}{*}{ Symptoms, n (\%) } & Dyspnea & $69(63.3)$ \\
\hline & Chest pain & $24(22.0)$ \\
\hline \multirow[t]{4}{*}{ IMIG stage, n (\%) } & 1 & $53(48.6)$ \\
\hline & 2 & $29(26.6)$ \\
\hline & $3 / 4$ & $25(22.9)$ \\
\hline & Unknown & $2(1.8)$ \\
\hline \multirow[t]{3}{*}{ ECOG-PS, n (\%) } & 0 & $41(37.6)$ \\
\hline & 1 & $41(37.6)$ \\
\hline & $2 / 3$ & $27(24.8)$ \\
\hline \multirow{4}{*}{$\begin{array}{l}\text { Granulocyte/lymphocyte } \\
\text { ratio, n (\%) }\end{array}$} & Median (range) & $3.2(0.1-88.2)$ \\
\hline & $<2.70$ & $36(33.0)$ \\
\hline & $2.70-4.13$ & $36(33.0)$ \\
\hline & $>4.13$ & $37(33.9)$ \\
\hline \multirow[t]{4}{*}{ Platelet count, $\times 10^{3} / \mu \mathrm{l}$} & Median (range) & $279(30-857)$ \\
\hline & $<245$ & $37(33.9)$ \\
\hline & $245-317$ & $36(33.0)$ \\
\hline & $>317$ & $36(33.0)$ \\
\hline SMRP, nM & Median (range) & $27.5(0.2-194.8)$ \\
\hline \multirow[t]{4}{*}{ Histotype, n (\%) } & Epithelioid & $78(71.6)$ \\
\hline & Sarcomatoiod & $17(15.6)$ \\
\hline & Biphasic & $12(11.0)$ \\
\hline & Unknown & $2(1.8)$ \\
\hline \multirow[t]{3}{*}{ Chemotherapy, n (\%) } & Yes & $68(62.4)$ \\
\hline & No & $18(16.5)$ \\
\hline & Unknown & $23(21.1)$ \\
\hline
\end{tabular}

ECOG-PS: Eastern Cooperative Oncology Group performance status; IMIG: International Mesothelioma Interest Group.

categorized according to tertiles (33rd and 66th percentile) of their corresponding distributions.

Overall survival (OS) time was defined as the period (months) between the date of diagnosis and the date of death or, alternatively, the date of the last follow-up examination.

Kaplan-Meier methodology was used to estimate OS probabilities within the three categories of SMRP and the log-rank test was applied to assess the statistical significance of the differences among survival probabilities (20).

The prognostic role of SMRP in PE was assessed through Cox regression modelling and expressed as death rate ratio (RR) and corresponding 95\% confidence intervaIs (95\% CI). All Cox regression analysis results were adjusted for potential imbalances in baseline patient characteristics (gender, age at diagnosis, disease stage, histotype and ECOG-PS). Akaike information criterion (20) was used as an index of information redundancy to verify the contribution of each characteristic to the model reliability. Differences among death rates were statistically evaluated using the likelihood ratio test (20). 


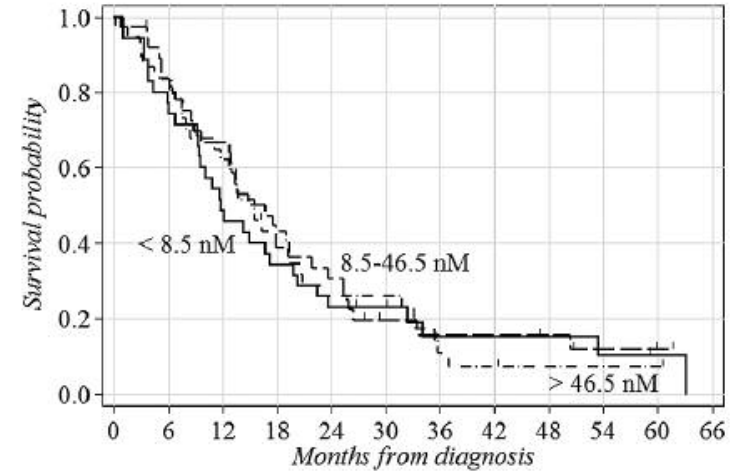

Figure 1. Probability of surviving for patients with malignant pleural mesothelioma according to soluble mesothelin-related protein (SMRP) level in pleural effusion ( $<8.5 \mathrm{nM}$; 8.5-46.5 $\mathrm{nM} ;>46.5 \mathrm{nM}$ ) estimated through the Kaplan-Meier method.

In order to point out a non-linear dose-response relationship potentially blurred by the categorization process, Cox regression modelling with a three-knot restricted cubic spline (RCS) was fitted to survival data (21). In this framework, the levels of SMRP in PE were log-transformed to reduce the influential effect of outlying data points.

All tests were two-tailed and a value of $p<0.05$ was considered statistically significant. All analyses were performed using Stata (Stata Statistical Software, Release 13.1, 2013; StataCorp. College Station, TX, USA).

\section{Results}

Patient characteristics. The present study included 109 MPM patients at diagnosis, before any treatment, enrolled from March 2008 to July 2011. The patients' mean age was 74 years (range $=45-98$ years) and $93(85.3 \%)$ were men. Regarding the MPM histotype, 78 (71.6\%) were epithelioid, 17 (15.6\%) sarcomatoid, 12 (11.0\%) biphasic and 2 (1.8\%) of unknown origin. By the International Mesothelioma Interest Group stage classification 53 (48.6\%), 29 (26.6\%) and $25(22.9 \%)$ patients had MPM stage 1, 2 and $3 / 4$ respectively, while for two $(1.8 \%)$ patients the stage was unknown. Forty-one (37.6\%) patients had an ECOG-PS of $0,41(37.6 \%)$ of 1 and $27(24.8 \%)$ higher than 1 .

Additional characteristics, including smoking habit, asbestos exposure, dyspnea, chest pain, granulocyte/ lymphocyte ratio, platelet count and chemotherapy treatment are shown in Table I.

By the end of the follow-up period in November 2016 (median follow-up time $=13.7$ months, range=0.2-63.2 months), 95 out of 109 patients $(87.2 \%)$ had died with a median survival time of 14.4 months (95\% CI=11.8-17.5 months) (Table II). The median baseline SMRP value was $27.5 \mathrm{nM}$ (range=0.2-194.8 $\mathrm{nM})$.

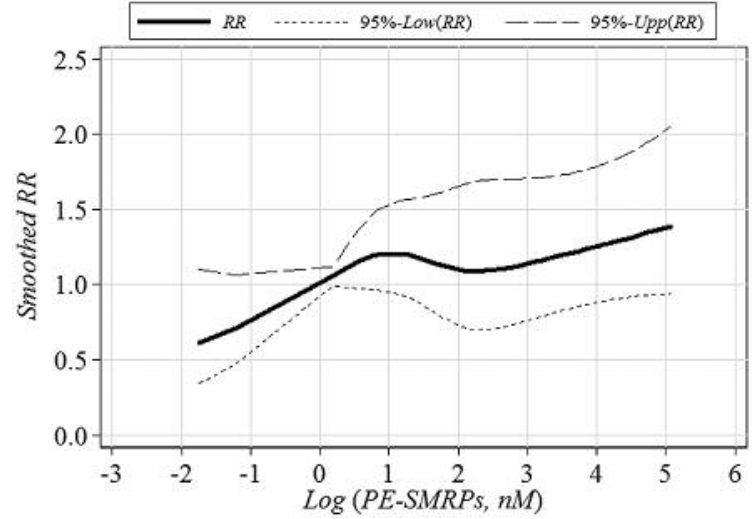

Figure 2. Effect of log-transformed soluble mesothelin-related protein $(S M R P)$ level in pleural effusion (PE) on the rate ratio $(R R)$ for death from malignant pleural mesothelioma as estimated through the Cox regression modelling adjusted for gender, age at diagnosis, disease stage, histotype and Eastern Cooperative Oncology Group performance status, using a three-knot restricted cubic spline (RCS). PE-SMRP levels were log-transformed in order to reduce the influential effect of potential outlying data points. 95\%-Low(RR)/95\%-Upp(RR): $95 \%$ Confidence intervals for $R R$.

Prognostic significance of PE-SMRP level in patients with $M P M$. No statistically significant differences were noted among OS probabilities estimated for the three SMRP categories $(<8.5 \mathrm{nM} ; 8.5-46.5 \mathrm{nM} ;>46.5 \mathrm{nM})$ through the Kaplan-Meier method ( $p=0.903$; Figure 1). Using Cox regression, a statistically non-significant increased trend in death rate was computed $(p=0.327)$ when the intermediate $(\mathrm{RR}=1.18 ; 95 \% \mathrm{CI}=0.66-2.13)$ and higher $(\mathrm{RR}=1.38 ; 95 \%$ $\mathrm{CI}=0.72-2.66) \mathrm{SMRP}$ levels were compared to the lower level $(\mathrm{RR}=1.00)$ (Table II). RCS included in the Cox regression equation confirmed such a slight tendency for increase, although the dose-response relationship appeared not to increase linearly over the range of log SMRP levels (Figure 2). In particular, a maximum RR of about 1.40 was observed when the log SMRP was about 5.2, which corresponds to an SMRP value of about $180.0 \mathrm{nM}$ (Figure 2).

\section{Discussion}

The identification of effective prognostic markers may play an important role for the clinician in the management of patients with MPM. In this context, epithelioid compared with the nonepithelioid histotype and poor ECOG-PS have been officially recognized as the best prognostic indicators by the two major prognostic scoring systems, the European Organization for Research and Treatment of Cancer and Cancer and Leukemia Group B. Other prognostic indicators considered, but not confirmed by all studies, are: male gender, high white blood cell count and lactate dehydrogenase value, and pleural primary site. 
Table II. Effect of soluble mesothelin-related protein (SMRP) in pleural effusion on the rate ratio for death from malignant pleural mesothelioma as estimated through the Cox regression model.

\begin{tabular}{|c|c|c|c|c|c|c|c|c|c|}
\hline \multirow[t]{2}{*}{$\operatorname{SMRP}(\mathrm{nM})$} & \multirow[t]{2}{*}{$\mathrm{N}$} & \multirow[t]{2}{*}{ Deaths, n (\%) } & \multicolumn{2}{|c|}{ Follow-up time (months) } & \multicolumn{2}{|c|}{ Survival time (months) } & \multirow[t]{2}{*}{$\mathrm{RR}$} & \multirow[t]{2}{*}{$95 \% \mathrm{CI}$} & \multirow[t]{2}{*}{$p$-Value } \\
\hline & & & Median & Range & Median & $95 \% \mathrm{CI}$ & & & \\
\hline$<8.5$ & 35 & $31(88.6 \%)$ & 11.8 & $0.7-63.2$ & 11.8 & $9.3-17.2$ & 1.00 & (Ref.) & 0.327 \\
\hline $8.5-46.5$ & 37 & $31(83.8 \%)$ & 14.8 & $1.0-61.4$ & 16.7 & $9.6-21.9$ & 1.18 & $0.66-2.13$ & \\
\hline$>46.5$ & 37 & $33(89.2 \%)$ & 15.5 & $0.2-60.4$ & 15.5 & $11.1-19.4$ & 1.38 & $0.72-2.66$ & \\
\hline Whole cohort & 109 & $95(87.2 \%)$ & 13.7 & $0.2-63.2$ & 14.4 & $11.8-17.5$ & - & - & - \\
\hline
\end{tabular}

RR: Rate ratio adjusted for gender, age at diagnosis, disease stage, histotype and Eastern Cooperative Oncology Group performance status; $95 \%$ CI: $95 \%$ confidence interval for RR; $p$ : probability level associated with the likelihood ratio test.; Ref.: reference category.

However, histotype and ECOG-PS remain the most significant prognostic predictors in MPM (3-5) and new prognostic markers need to be identified for effective routine application.

PE can be an important source of information for assessing prognosis in patients with MPM. It is present in the majority of such patients and is closely related to the neoplasm. Indeed, being routinely withdrawn for therapy and used for cytological diagnosis, the collection of PE does not represent an excessive extra workload in terms of time and cost. Among the molecules that can be analyzed, SMRP appeared to be very promising because its level in body fluids can represent an index of MPM tumor size $(8,22)$, which is associated with a poor prognosis (7).

The prognostic value of SMRP in PE has been investigated in recent years but the results of published studies are not uniform and conclusive. In particular, two groups have investigated whether the determination of SMRP level in PE in patients with MPM may have a prognostic significance but they reported conclusions in conflict with each other. Creaney et al., studying a group of 52 patients at diagnosis (histotype: 15 epithelioid, 14 non-epithelioid, 23 unknown), did not find a significant difference in survival between non-sarcomatoid groups according to the median level of SMRP in PE (about $26 \mathrm{nM}$ ) (17). These results were later confirmed in a group of 82 patients (histotype: 32 epithelioid, 21 non-epithelioid and 29 unknown) (18). In contrast, Yamada et al. in 45 patients with MPM (37 with epithelioid and eight with non-epithelioid) found that at the cut-off of $10 \mathrm{nM}$, patients with PE-SMRP level $>10 \mathrm{nM}$ had significantly better survival (19).

In our study, performed on 109 samples (78 epithelioid, 29 non-epithelioid and 2 unknown) using tertile-based (8.5 and $46.5 \mathrm{nM}$ ) categories for SMRP in PE, both KaplanMeier and Cox modelling show no statistically significant difference in survival.

In order to identify any non-linear dose-response relationship between SMRP in PE and death rate potentially overlooked because of the categorization of SMRP, RCS was fitted to survival data through the Cox regression equation. RCS, which is a flexible and smoothed function of logtransformed data (21), showed only a slightly non-monotonic dose-response relationship.

Ultimately, our results, obtained from a cohort of Italian patients with MPM, seem to support the hypothesis that a higher SMRP level in PE at diagnosis is weakly associated with a shorter survival of patients with MPM. Therefore, we believe that the disagreement among different studies (1719 ) is not only related to the low number of enrolled patients but especially attributable to patients' clinical heterogeneity stemming essentially from different histological subtypes, therapeutic protocols and ECOG-PS scores.

In conclusion, SMRP detection in PE, in our opinion, is not recommended for use in routine application in the clinical management of patients with MPM. However, determination of the SMRP levels in PE remains crucial in defining the diagnosis of MPM.

\section{Conflicts of Interest}

The Authors attest that no potential conflicts of interest exist with any company/organization whose products or services may be discussed in this article.

\section{Authors' Contributions}

V.F., M.P.P. and S.R. wrote the article: V.F. performed all statistical analyses; P.F., M.C.F., M.T. and R.C. prepared PE samples for analysis and storage; C.R. and P.D. performed histological diagnosis of MPM; U.G. performed radiological diagnosis and collected prognostic data; A.V. and G.B. collected clinical data and managed patients with MPM; P.A.C. collected PE and performed the first clinical diagnosis of MPM.

\section{Acknowledgements}

This work was supported by AIL (Sezione Francesca Lanzone) La Spezia, Comitato Assistenza Malati e Lotta Contro i Tumori, 
Sarzana, to SR and Italian Ministry of Health (Ricerca Corrente 2019), Italy to MPP and VF. The Authors thank A. Camaiora, V. Balestracci, R. Tome and L. Lombardi for collecting the samples, the doctors and staff of the Pneumology Division (San Bartolomeo Hospital, Sarzana) for collecting mesothelioma patients and Dr. E. Battolla of Clinical Pathology Division (Sant'Andrea Hospital, La Spezia) that performed the histological diagnosis.

\section{References}

1 Bibby AC, Tsim S, Kanellakis N, Ball H, Talbot DC, Blyth KG, Maskell NA, Psallidas I: Malignant pleural mesothelioma: An update on investigation, diagnosis and treatment. Eur Respir Rev 25: 472-486, 2016. PMID: 27903668. DOI: 10.1183/ $16000617.0063-2016$

2 Katzman D, Sterman DH: Updates in the diagnosis and treatment of malignant pleural mesothelioma. Curr Opin Pulm Med 24: 319-326, 2018. PMID: 29553973. DOI: 10.1097/ MCP.0000000000000489.

3 Billé A, Krug LM, Woo KM, Rusch VW and Zauderer MG: Contemporary analysis of prognostic factors in patients with unresectable malignant pleural mesothelioma. J Thorac Oncol 11: 249-255, 2016. PMID: 26845118. DOI: 10.1016/j.jtho. 2015.10.003

4 Pass HI, Goparaju C, Espin-Garcia O, Donington J, Carbone M, Patel D, Chen Z, Feld R, Cho J, Gadgeel S, Wozniak A, Chachoua A, Leighl N, Tsao MS, de Perrot M, Xu W and Liu G: Plasma biomarker enrichment of clinical prognostic indices in malignant pleural mesothelioma. J Thorac Oncol 11: 900-909, 2016. PMID: 26903362. DOI: 10.1016/j.jtho.2016.02.006

5 Sun HH, Vaynblat A and Pass HI: Diagnosis and prognosis review of biomarkers for mesothelioma. Ann Transl Med 5: 244, 2017. PMID: 28706912. DOI: 10.21037/atm.2017.06.60

6 Tian L, Zeng R, Wang X, Shen C, Lai Y, Wang M and Che G: Prognostic significance of soluble mesothelin in malignant pleural mesothelioma: A meta-analysis. Oncotarget 8: 4642546435, 2017. PMID: 28507279. DOI: 10.18632/oncotarget. 17436

7 Pass HI, Wali A, Tang N, Ivanova A, Ivanov S, Harbut M, Carbone $\mathrm{M}$ and Allard $\mathrm{J}$ : Soluble mesothelin-related peptide level elevation in mesothelioma serum and pleural effusions. Ann Thorac Surg 85: 265-272, 2008. PMID: 18154821. DOI: 10.1016/j.athoracsur.2007.07.042

8 Creaney J, Francis RJ, Dick IM, Musk AW, Robinson BW, Byrne MJ and Nowak AK: Serum soluble mesothelin concentrations in malignant pleural mesothelioma: Relationship to tumor volume, clinical stage and changes in tumor burden Clin Cancer Res 17: 1181-1189, 2011. PMID: 21177406. DOI: 10.1158/1078-0432.CCR-10-1929

9 Chang K and Pastan I: Molecular cloning of mesothelin a differentiation antigen present on mesothelium, mesotheliomas, and ovarian cancers. Proc Natl Acad Sci USA 93: 136-140, 1996. PMID: 8552591. DOI: 10.1073/pnas.93.1.136

10 Ordóñez NG: Value of mesothelin immunostaining in the diagnosis of mesothelioma. Mod Pathol 16: 192-197, 2003 PMID: 12640097. DOI: 10.1097/01.MP.0000056981.16578.C3

11 Robinson BW, Creaney J, Lake R, Nowak A, Musk AW, de Klerk N, Winzell P, Hellstrom KE and Hellstrom I: Mesothelinfamily proteins and diagnosis of mesothelioma. Lancet 36: 16121616, 2003. PMID: 14630441. DOI: 10.1016/S0140-6736(03) $14794-0$
12 Canessa PA, Franceschini MC, Ferro P, Battola E, Dessanti P, Manta C, Sivori M, Pezzi R, Fontana V, Fedeli F, Pistillo MP and Roncella S: Evaluation of soluble mesothelin-related peptide as a diagnostic marker of malignant pleural mesothelioma effusions: Its contribution to cytology. Cancer Invest 31: 43-50, 2013. PMID: 23249166. DOI: 10.3109/07357907.2012.749265

13 Cui A, Jin XG, Zhai K, Tong ZH and Shi HZ: Diagnostic values of soluble mesothelin-related peptides for malignant pleural mesothelioma: Updated meta-analysis. BMJ Open 4: e004145, 2014. PMID: 24566531. DOI: 10.1136/bmjopen-2013-004145

14 Bonotti A, Foddis R, Landi S, Melaiu O, De Santi C, Giusti L, Donadio E, Ciregia F, Mazzoni MR, Lucacchini A, Bovenzi M, Comar M, Pantani E, Pistelli A and Cristaudo A: A Novel panel of serum biomarkers for MPM diagnosis. Dis Markers 2017: 3510984, 2017. PMID: 28348450. DOI: 10.1155/2017/3510984

15 Davies HE, Sadler RS, Bielsa S, Maskell NA, Rahman NM, Davies RJ, Ferry BL and Lee YC: Clinical impact and reliability of pleural fluid mesothelin in undiagnosed pleural effusions. Am J Respir Crit Care Med 180: 437-444, 2009. PMID: 19299498. DOI: $10.1164 / \mathrm{rccm} .200811-17290 \mathrm{C}$

16 Scherpereel A, Grigoriu B, Conti M, Gey T, Grégoire M, Copin MC, Devos P, Chahine B, Porte H and Lassalle P: Soluble mesothelin-related peptides in the diagnosis of malignant pleural mesothelioma. Am J Respir Crit Care Med 173: 1155-1160, 2006. PMID: 16456138. DOI: 10.1164/rccm.200511-1789OC

17 Creaney J, Yeoman D, Naumoff LK, Hof M, Segal A, Musk AW, De Klerk N, Horick N, Skates SJ and Robinson BW: Soluble mesothelin in effusions: A useful tool for the diagnosis of malignant mesothelioma. Thorax 62: 569-576, 2007. PMID: 17356060. DOI: $10.1136 /$ thx .2006 .068114

18 Creaney J, Dick IM, Meniawy TM, Leong SL, Leon JS, Demelker Y, Segal A, Musk AW, Lee YC, Skates SJ, Nowak AK and Robinson BW: Comparison of fibulin-3 and mesothelin as markers in malignant mesothelioma. Thorax 69: 895-902, 2014. PMID: 25037982. DOI: 10.1136/thoraxjnl-2014-205205

19 Yamada S, Tabata C, Tabata R, Fukuoka K and Nakano T: Clinical significance of pleural effusion mesothelin in malignant pleural mesothelioma. Clin Chem Lab Med 49: 1721-1726, 2011. PMID: 21692685. DOI: 10.1515/CCLM.2011.242

20 Marubini E and Valsecchi MG: Analyzing survival data from clinical trials and observational studies. John Wiley and Sons, New York, 1995.

21 Harrell FE Jr: Regression Modelling Strategies. Second Edition. New York, Springer Verlag, 2015.

22 Fontana V, Vigani A, Pistillo MP, Giannoni U, Rosemberg I, Canessa PA, Berisso G, Ferro P, Franceschini MC, Tonarelli M and Roncella $S$ : The correlation of serum mesothelin level with pleural thickness in malignant pleural mesothelioma makes it a valuable tool for monitoring tumor progression. J Thorac Oncol 14: e92-e94, 2019. PMID: 31027749 DOI: 10.1016/j.jtho. 2018.12.026
Received July 22, 2019

Revised August 6, 2019

Accepted August 9, 2019 